\title{
Determining Students' Conceptual Understandings of Physics Concepts
}

\section{OPEN ACCESS}

Manuscript ID:

EDU-2020-08032908

Volume: 8

Issue: 3

Month: June

Year: 2020

P-ISSN: 2320-2653

E-ISSN: 2582-1334

Received: 17.04.2020

Accepted: 15.05.2020

Published: 01.06.2020

Citation:

Ozkan, Gulbin, and Unsal Umdu Topsakal.

"Determining Students'

Conceptual Understandings of Physics Concepts." Shanlax International Journal of Education, vol. 8, no. 3, 2020, pp. 1-5.

DOI:

https://doi.org/10.34293/ education.v8i3.2908

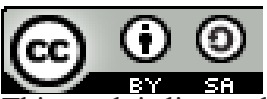

This work is licensed under a Creative Commons Attribution-ShareAlike 4.0 International License

\section{Gulbin Ozkan}

Research Assistant, Department of Mathematics and Science Education

Faculty of Education, Yildiz Technical University, Istanbul, Turkey

(D) https://orcid.org/0000-0001-8390-5259

\section{Unsal Umdu Topsakal}

Professor, Department of Mathematics and Science Education, Faculty of Education Yildiz Technical University, Istanbul, Turkey

\section{Abstract}

In this study, it was aimed to determine the students' conceptual understanding and misconceptions about the concepts in the 8th grade Matter and Properties unit. Students $(n=180)$ of two middle schools in Istanbul Province participated in the study. The qualitative research method was used to determine students' conceptual understanding. A paper-and-pencil questionnaire consisting of six questions was applied as a data collection tool. Student responses to the questionnaires were subcategories by content analysis, and the percentages of the responses were determined. As a result of the findings obtained from the study, it was seen that 8th-grade students had some conceptual deficiencies and misconceptions about pressure and buoyancy.

Keywords: Misconceptions, Science, Physics education, Middle school students, Conceptual understanding.

\section{Introduction}

Physics appears in many ways in many areas of daily life, and experiences enable us to develop some concepts related to physics; however, the concepts that the individual gained with his past lives may not match some scientific facts. These experiences, which are incompatible with scientific facts, lead to the emergence of learning products called misconceptions in the literature.

Misconceptions are the mismatch of the scientific definition of the concepts and the definitions that the student creates in his mind (Gönen \& Akgün, 2005). Baki (1999) defined misconceptions as behaviors that result from students' wrong beliefs and experiences. Çakır and Yürük (1999), on the other hand, explained misconceptions as information preventing the teaching and learning of concepts that are contrary to scientific facts and proved by science.

Students start their physics education with information that differs from scientific realities and prevents the teaching of effective physics (Dykstra et al., 1992). The nature of students' understanding of scientific concepts and phenomena are essential components of education because students come to the course with many alternative concepts that interfere with scientific principles and concepts.

Studies in the literature have shown that the majority of students come to science lessons with pre-teaching knowledge or beliefs about the phenomena and concepts to be taught and that many students develop only a limited understanding of science concepts following the instruction (Duit \& Treagust, 2003). Misconceptions that hinder learning are emphasized in various studies. 
For this reason, before starting any subject teaching, students' prior concepts and misconceptions, if any, should be determined, and the teaching activities should be arranged in line with this information obtained (to eliminate existing misconceptions). Misconceptions resist change (Smith et al., 1993). It is important to identify misconceptions and to learn deficiencies to perform meaningful learning. This research aims to determine the preliminary knowledge and misconceptions of 8th-grade students about pressure and buoyancy in the "Matter and Properties" unit.

\section{Method}

Qualitative research methods were used in this study. This approach helps researchers better understand and explain the meaning-making process.

\section{Sample}

This study was carried out with a total of 180 students studying in the 8 th grades of two middle schools in Istanbul. The students received basic education on the subject in primary education.

\section{Data Collection Tool}

The data were collected by a questionnaire consisting of 8 open-ended questions. While preparing the questions, outputs in the 8th-grade Physics Curriculum were taken into consideration. After the questionnaire was prepared, it was checked by three physics teachers with more than 10 years of experience in different middle Schools and a faculty member specializing in science education to test the scope and validity. Then, it was rearranged in line with the recommendations.

The questionnaire consists of the pressure and buoyancy of the "Substance and Properties" unit in the 8th-grade teaching program. The topics of the open-ended questionnaire form questions are given in Table 1.

Table 1: Topics of the Open-ended Questionnaire Form

\begin{tabular}{|c|l|l|}
\hline Item & \multicolumn{1}{|c|}{ Topic } & \multicolumn{1}{c|}{ Content } \\
\hline 1 & Fluid pressure & Liquid Flush Speed \\
\hline 2 & Buoyancy & Interpreting String Tensions \\
\hline
\end{tabular}

\begin{tabular}{|c|l|l|}
\hline 3 & Buoyancy & $\begin{array}{l}\text { Density-Buoyancy Force } \\
\text { Relationship }\end{array}$ \\
\hline 4 & Solid Pressure & $\begin{array}{l}\text { Surface Area-Pressure } \\
\text { Relationship }\end{array}$ \\
\hline 5 & Buoyancy & Non-mixing Liquids \\
\hline 6 & $\begin{array}{l}\text { Bernoulli } \\
\text { Principle }\end{array}$ & $\begin{array}{l}\text { Factors Affecting Fluid } \\
\text { Pressure }\end{array}$ \\
\hline 7 & Buoyancy & $\begin{array}{l}\text { Density-Weight-Buoyancy } \\
\text { Force Relationship }\end{array}$ \\
\hline 8 & Gas Pressure & Open Air Pressure \\
\hline
\end{tabular}

The answers given by the students to the openended questions in the questionnaire were divided into subcategories by making content analysis. The data were analyzed separately by two researchers to ensure the reliability of the scoring. The agreement between the two raters was calculated as 95 percent.

\section{Findings}

The distribution of students' answers according to the percentages of the questions in the questionnaire is presented separately for each question.

In the first question on the subject of liquid pressure, two containers filled with liquids of different density are illustrated to the students. It is said that there are two holes in the first container, one at the bottom and one at the top, and the second container is a hole at the same height as the upper one (Figure 1). The students were asked to list the flushing speed of the water flowing through these holes and explain the reasons.

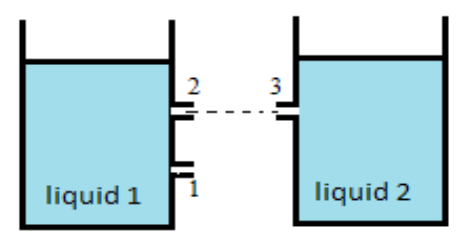

\section{Figure 1: Figure in the First Question}

While $37.5 \%$ of the students answered the first question correctly, $62.5 \%$ of the students gave partially correct or false answers $16.4 \%$ of the students who responded wrongly thought that the flow rate of the liquid depends on the density of the liquid through a hole opened from the side surface of a liquid-filled container. $46.1 \%$ of the students answered partially correctly and stated that through a hole opened from the side surface of a container 
filled with liquid, the flow rate of the liquid depends on both the density of the liquid and the height of the liquid to the open surface.

In the second question addressed to the students, it is aimed that the students also apply their knowledge learned in the "Force and Motion" unit in buoyancy. In this question, three objects of equal volume, connected to dynamometers, are left in the same liquid. They were asked to interpret the relationship between the densities of these three bodies, given the relationship between the string tensions (Figure 2).

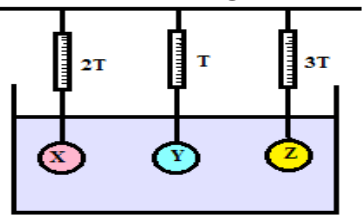

\section{Figure 2: Figure in the Second Question}

While $61.8 \%$ of the students answered this question correctly, $24.2 \%$ did not answer the question. It was determined that the remaining $14 \%$ had the misconception. $4.8 \%$ of the students stated that the tension in the rope on which the big objects are hanging is smaller. Also, since the lifting forces applied to the objects are equal, the percentage of students who state that their bodies are equal is 9.2.

In the third question prepared within the scope of the buoyant force, they were asked to determine the relationship between the bodies of equal bodies with different volumes in equilibrium in a liquid in a container shown by the figure and justify their answers (Figure 3).

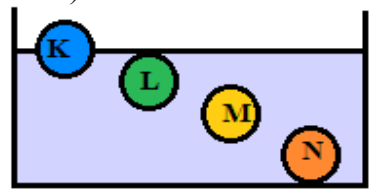

Figure 3: Figure in the Third Question

$65.4 \%$ of the students answered this question correctly. However, $28.5 \%$ responded to the body, which is close to the liquid surface, and the least buoyant force applied to the sinking body. $6.13 \%$ of these students wrote that the lifting forces applied are equal since all objects are in the same fluid. The students were able to establish the relationship of buoyancy with the third question, but they had difficulties in commenting on the density of the suspended objects.
In the fourth question, students were given an object with a base of $2 \mathrm{~S}$ and a pressure P. They were asked to interpret how P, P1, P2 sorting would be when the body weights were different, but their pressure was divided into $\mathrm{P} 1$ and $\mathrm{P} 2$ with the surface areas equal (Figure 4).

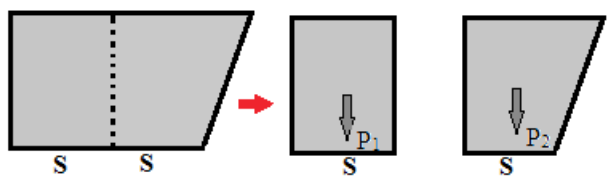

Figure 4: Figure in the Fourth Question

When looking at the percentages of the answers given to this question, it was determined that $50.9 \%$ of the students had misconceptions and missing learning. $21.9 \%$ of the students think that the fragmentation of the objects does not change the pressure applied to the base. $7.83 \%$ of the students responded to the pressure applied to the base because the surface areas of the parts are equal and less than the whole body, while the pressure applied by the parts to the base is equal and greater than the whole body. $6.67 \%$ wrote that the piece, which has a low weight, applies more pressure than the whole. The students responded to this question as a result of some erroneous operations.

To interpret the buoyancy applied to the object in liquids that do not mix, the students were given the position of the object in an irregular container (Figure 5). If the shape is reversed, students are asked to draw the position of the object.

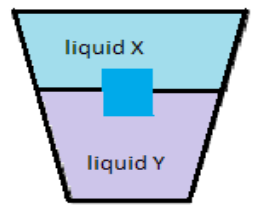

Figure 5: Figure in the Fifth Question

While only $12.1 \%$ of the students answered the question correctly, $6.3 \%$ of them justified their answers correctly. Incomplete conceptualization or misconception was found in $87.9 \%$ of the students. Some of the students (28\%) argued that there would be no change in the position of the object. $47.9 \%$ stated that since the Y liquid will increase more, the lifting force will increase, and less of the object will sink. 
In the sixth question posed to determine the students' misconceptions and conceptual deficiencies about the pressure of fluids, it was asked why the faucets in our houses have a gradually narrowing structure.

$87.3 \%$ of the students, that is almost all, interpreted the purpose of the taps completely differently. Some of them stated the opposite of the Bernoulli Principle that the pressure increase in liquids is directly proportional to the flow rate.

In the seventh question, the balanced position of the object connected to the rope is drawn from the bottom of a container filled with liquid. In the question that string tension is different from zero, students were asked to interpret the relationship between the density of the body and the density of the liquid, and between the weight of the body and the buoyant force (Figure 6).

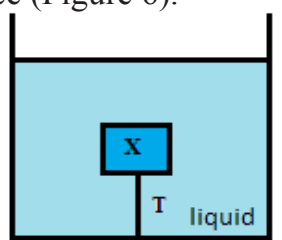

\section{Figure 6: Figure in the Seventh Question}

While $32.7 \%$ of the students answered this question with the correct reasons, $67.3 \%$ of them had a lack of prior knowledge. While $54.8 \%$ of the students cannot compare the density of the object with the density of the liquid correctly, $12.5 \%$ cannot accurately explain the relationship between the weight of the object and the buoyancy of the liquid.

In the eighth question, students were asked the reason for a situation that they frequently encounter in daily life. When they pull the air in the juice pack with a pipette, they were asked to explain what the reason was for the box to shrink with their reasons. While $51 \%$ of the students responded correctly to this question, which aimed to interpret the presence of open-air pressure, $49 \%$ had some deficiencies and misconceptions. $12 \%$ of the students explained that the reason of the shrinkage of the box was that the temperature in our breath increased the gas pressure, $3 \%$ of the liquid remained in the lifting force, $17 \%$ of the liquids were transmitting the pressure in the same way, and $17 \%$ of the pressure in the box increased.

The misconceptions students have are summarized in Table 2.
Table 2: Misconceptions Identified in Students

\begin{tabular}{|c|c|}
\hline tem & Misconception \\
\hline 1 & $\begin{array}{l}\text { The flow rate of the liquid through a hole } \\
\text { opened from the side surface of a liquid-filled } \\
\text { container depends on the density of the liquid } \\
\text { and the open-air pressure. }\end{array}$ \\
\hline 2 & $\begin{array}{l}\text { The buoyant force applied to the objects de- } \\
\text { pends on the tensile force on the rope to which } \\
\text { they are suspended from above. } \\
\text { When the buoyancy applied to the objects is } \\
\text { equal, the bodies of the bodies are also equal. }\end{array}$ \\
\hline 3 & $\begin{array}{l}\text { The object that is close to the liquid surface is } \\
\text { mostly applied to the sinking object, and the } \\
\text { least buoyant force is applied. } \\
\text { The lifting forces applied to all objects in the } \\
\text { same fluid are equal. }\end{array}$ \\
\hline 4 & $\begin{array}{l}\text { Fragmentation of objects never changes the } \\
\text { pressure on the base. } \\
\text { The piece, which has a low weight, applies } \\
\text { more pressure than the whole. } \\
\text { The surface areas are also equal to the pressures } \\
\text { applied by the parts to the base and are smaller / } \\
\text { bigger than the whole body. }\end{array}$ \\
\hline 5 & $\begin{array}{l}\text { The object, which is placed in two unmixed } \\
\text { liquids in an irregular container, remains in } \\
\text { the same position when the container is turned } \\
\text { upside down. }\end{array}$ \\
\hline 6 & $\begin{array}{l}\text { The pressure increase in fluids is directly pro- } \\
\text { portional to the flow rate. }\end{array}$ \\
\hline 7 & $\begin{array}{l}\mathrm{d} \text { weight depend on the tension in } \\
\text { the objects attached to the base. }\end{array}$ \\
\hline 8 & $\begin{array}{l}\text { The element that balances the inner pressure } \\
\text { and outer pressure is temperature/liquid } \\
\text { pressure (not open-air pressure). }\end{array}$ \\
\hline
\end{tabular}

\section{Discussion and Conclusions}

Considering the findings obtained from the study, it is seen that there are many conceptual deficiencies in students' pressure and buoyancy. Since the issues of pressure and buoyancy are among the subjects that students can frequently encounter in daily life, students develop many concepts in these subjects.

The issue of pressure, especially the pressure of liquids and gases, is a subject that is familiar with the experience of students in many areas of daily life, which they find interesting (such as drinking juice with a straw, divers wearing special clothes for divers and astronauts), and which will form a basis 
for education in later educational institutions. It is important to realize the conceptual changes related to the pressure of liquids and gases since the particles underlying this subject require the knowledge of the particulate structure and physical processes that define the pressure (for example, the particles that makeup water and air are constantly in motion and apply pressure to all parts of the container in which they are located) (She, 2002).

To realize effective learning, it is necessary to eliminate misconceptions first. Different teaching approaches can be used to overcome students' misconceptions.

Today, when the knowledge of teachers is constantly increasing, a big task falls. While organizing the education and training environment, teachers should show students the ways to access information instead of presenting the information ready. Considering that today there is a shift from traditional teaching methods to contemporary teaching methods in the education system, more contemporary teaching methods should be included in the organization of educational activities. This will help students realize full learning instead of incomplete conceptualization.

\section{References}

Baki, A. "Cebirle ilgili işlem yanılgılarının değerlendirilmesi." Science Education Symposium, 1999, pp. 23-25.

Cakır, S.Ö, and Yürük. N. "Oksijenli ve oksijensiz solunum konusunda kavram yanılgıları teşhis testinin geliştirilmesi ve uygulanması." Science Education Symposium, 1999, pp. 23-25.

Chiu, Mei-Hung. "Assessing Students' Conceptual Understanding in Science: An Introduction about a National Project in Taiwan." International Journal of Science Education, vol. 29, no. 4, 2007.

Duit, Reinders and David F Treagust. "Conceptual Change: A Powerful Framework for Improving Science Teaching and Learning." International Journal of Science Education, vol. 25, no. 6, 2003, pp. 671-688.

Dykstra, Dewey I, et al. "Studying Conceptual Change in Learning Physics." Science Education, vol. 76, no. 6, 1992, pp. 615-652.

Gönen, S, and Akgün, A. "The Investigation of Applicability of Worksheet was Developed about Relationship between Heat and Temperature Concepts." Elektronik Sosyal Bilimler Dergisi, vol. 3, no. 11, 2005, pp. 92106.

Kola, Aina. "Investigating the Conceptual Understanding of Physics through an Interactive Lecture Engagement." Cumhuriyet International Journal of Education, vol. 6, no. 1, 2017, pp. 82-96.

Saricayir, Hakan. "Determining Students' Conceptual Understanding Level of Thermodynamics." Journal of Education and Training Studies, vol. 4, no. 6, 2016, pp. 69-79.

She, H. C. "Concepts of a Higher Hierarchical Level Require more Dual Situated Learning Events for Conceptual Change: A Study of Air Pressure and Buoyancy." International Journal of Science Education, vol. 24, no. 9, 2002, pp. 981-996.

Smith, J.P., et al. "Misconceptions Reconceived: A Constructivist Analysis of Knowledge in Transition." The Journal of Learning Sciences, vol. 3, no. 2, 1993, pp. 115-183.

\section{Authors Details}

Gulbin Ozkan, Research Assistant, Department of Mathematics and Science Education, Faculty of Education, Yildiz Technical University, Istanbul, Turkey,Email ID: gozkan@yildiz.edu.tr.

Unsal Umdu Topsakal, Professor, Department of Mathematics and Science Education, Faculty of Education, Yildiz Technical University, Istanbul, Turkey,E-mail ID: topsakal@yildiz.edu.tr. 